\title{
Usos do tempo, entre passado e porvir: uma introdução
}

\section{Uses of time, between the past and the future: an introduction}

Enviado em: 30/09/2020

Aceito em: 05/01/2021

Paula Godinho ${ }^{1}$

\begin{abstract}
El pasado es la única temporada que crece cada día. Desde el hoy solemos contemplarlo con un poco de angustia. Y nunca esta completo. La memoria se queda apenas con fragmentos, que no siempre son los más relevantes.
\end{abstract}

Mário Benedetti, Vivir adrede

Têm razão os cépticos quando afirmam que a história da humanidade é uma interminável sucessão de ocasiões perdidas. Felizmente, graças à inesgotável generosidade da imaginação, cá vamos suprimindo as faltas, preenchendo as lacunas o melhor que se pode, rompendo passagens em becos sem saída e que sem saída irão continuar, inventando chaves para abrir portas órfãs de fechadura ou que nunca a tiveram"

José Saramago, A viagem do Elefante

Neste dossiê interroga-se os usos do tempo no campo conturbado e confluente entre ciências sociais e humanas como a história, a antropologia, a arqueologia, a museologia, convocando igualmente a literatura e os estudos culturais. O objetivo central é uma abordagem dos usos do passado e da construção do futuro, que possa interrogar o crescendo dos estudos sobre a memória, o património e o anti-património, a relação com as fontes orais, os arquivos e os museus, ao mesmo tempo que se debate a teoria e os métodos, e se convocam saberes de fronteira de várias disciplinas.

As aproximações acerca da memória, objetificada como património, sobretudo desde os anos 1980, correspondem a um estado do saber e das sociedades, quando o otimismo se diluiu e o futuro pareceu tornar-se passado. Essa viragem, coetânea de mudanças ao nível das sociedades, requereu uma reflexão sobre os usos do passado,

1 - Paula Godinho (PhD Antropologia, FCSH-NOVA), investigadora IHC-NOVA e professora associada com agregação no Departamento de Antropologia da FCSH-Universidade Nova de Lisboa. Fundadora da Red(e) Ibero-Americana Resistência e/y Memória e membro do grupo de trabalho CLACSO "Izquierdas: praxis y transformación social" (2019-2022). Prémio XesúsTaboadaChivite, 2008 (Galiza, Espanha), Xuíza honorária pela Associación de Amigos do Couto Mixto, Galiza, 2011, Arraiana Maior pela Associación Arraianos (Galiza, 2017). Vários anos de trabalho de campo em Portugal, na fronteira, na Galiza, no Brasil, sobre reprodução social, festas e rituais, resistência e movimentos sociais, usos políticos da memória e práticas do património, processos de emblematização, turistificação e mercantilização da cultura, topografias do poder, culturas de fronteira e nacionalismos de diáspora. 
como artefacto do presente, sujeitos às relações de forças dentro das sociedades, que indagam igualmente o lugar do porvir, em tempos de futuros pretéritos. Este dossiê resulta do aprofundamento dos saberes no âmbito de um conjunto de relações estabelecidas a partir da linha de investigação «Usos do Passado, Memória e Património Cultural» do Instituto de História Contemporânea da Universidade Nova de Lisboa, e congrega colegas de vários centros de investigação europeus, da Universidade Federal do Ceará, da Universidad Nacional Autonoma de Mexico, da Red(e) Ibero-Americana Resistência e/y Memória e do projectoREVFAIL: ReversingtheGenealogiesofUnsuccess, 16th-19th centuries, no âmbito do programa RISE, Marie Sklodowska Curie Actions.

Construir nações, com o kit do-it-youself para o realizar, requer igualmente intervenções que se evidenciam na própria paisagem. No texto de XurxoAyán Vila, Olga Novo e Xosé Gago García-Brabo somos desafiadas a olhar para a resistência de comunidades rurais envelhecidas de uma região da Galiza (Espanha) que foi historicamente conhecida como Terra de Lemos. O governo autonómico galego vem tentando que uma região vinícola do interior da Galiza seja declarada Património da Humanidade pela UNESCO. Num texto delicado, os autores demonstram-nos que somos o que sonhamos, num local em que as vides e as vidas se irmanam, numa humanidade que habita o património. Com base num trabalho que é tanto de arqueologia como de etnografia e poesia, os autores demonstram como desde o final do séc. XIX a elite intelectual construiu um relato hegemónico acerca desse espaço, a que chamaram Ribeira Sacra, numa remissão para os mosteiros e edificações medievais ali concentradas. Confrontaram-se com os mitos veiculados por fontes eruditas, com uma filiação ideológica no nacional-catolicismo espanhol, e com os dados da ciência e do imaginário coletivo das comunidades locais, que evidenciavam a marginalização destes últimos. O texto apresentado é o resultado de um projeto interdisciplinar, Adegas da Memoria, com enfoque na paisagem cultural de uma paróquia galega de montanha, que desenvolve uma Arqueologia Rural com uma estreita relação com a tradição oral, que parte desta e que visa dar voz a uma comunidade camponesa subalternizada pelo discurso tecnocrático oficial. Através de uma cartografia simbólica utilizada pelos vizinhos, os arqueólogos procederam a prospeções e escavações arqueológicas, fizeram entrevistas e uma série documental, num trabalho de etnoarqueología, arqueología emocional e fenomenologia da paisagem. Articulam aqui relatos patrimoniais contra-hegemónicos, reivindicam o carácter resiliente dos camponeses e camponesas da zoa, e reativam a tradição oral 
como ferramenta para manter a esperança, com um discurso arqueopoético e arqueoético. Tornam-se igualmente arqueólogos psicanalistas, com capacidade para articular em interfaces dolorosas com cicatrizes que ainda supuram devido a traumas do passado. A guerra civil espanhola, com perseguições, mortos e deserções, mantém-se repleta de silêncios de sepulcro e de traumas coletivos. Os autores e a autora reivindicam a total validade da memória oral do mundo rural como fundamento empírico para um relato científico rigoroso sobre a genealogia e o devir histórico daquela paisagem cultural.

Reportando-me igualmente à memória de uma ditadura e ao trauma inerente, interrogo as recordações sensíveis de uma presa política do fascismo português. A partir da inspiração de Jacques Rancière acerca da partilha do sensível, centrei-me em materiais do arquivo pessoal de Aurora Rodrigues, uma presa política do tardofascismo português, detida em 1973 e vítima de tortura. Aurora Rodrigues tinha então 21 anos e colaborava com um movimento maoista, o MRPP (Movimento Reorganizativo do Partido do Proletariado), muito ativo no final da ditadura, e com ações corajosas e de grande visibilidade. Investigo material sensível, depois de ter também consultado os arquivos da polícia política e de ter participado na recolha, transcrição, organização e publicação da história de vida de Aurora Rodrigues. Neste texto, proponho uma reflexão sobre os materiais que produziu na cadeia e que aí recebeu, que permitem aceder a uma experiência de resistência, assente nas memórias traumáticas da jovem maoista. Jacques Rancière desafia-nos a detetar 0 sistema de evidências sensíveis que cria noções de comum, e que inscreve a ordem do mundo nas categorias do visível e do dizível. Esse comum é um idioma coletivo, resistente, que recusa a ordem da dominação. Foi uma arma dos grupos subalternos e perseguidos - uma arma dos fracos, no sentido que lhe deu James C. Scott. No texto, percorro a vida prisional de uma resistente à longa ditadura portuguesa (1926-1974), reportando-me a cartas e a um caderno que conseguiu resgatar da cadeia. $O$ sofrimento tangível da detida emerge, de forma elíptica, nesses escritos de prisão e nas missivas recebidas, enviadas pela família extensa, mobilizada neste momento de crise. Esta rememoração sensível - e o arquivo de Aurora Rodrigues -, serve de interrogação às políticas de memória nas sociedades ibéricas: Portugal e Espanha tiveram passados ditatoriais longos e uma guerra civil/colonial. Na passagem para a democracia, esse passado manteve obscurecido e lacrado o combate dos que resistiram às ditaduras, remetidos para a ucronia ou para presentes alternativos. Porém, como recorda o historiador catalão Josep Fontana, para edificar um novo 
futuro, há que lembrar que as conquistas políticas, económicas e sociais obtidas com as transições par as democracias não resultaram de deuses ex machina, mas das lutas, alicerçadas na sensibilidade e na edificação em comum por parte dos resistentes às ditaduras.

Mostrar a inscrição do passado e interroga-la é o objetivo do texto de Francisco Régis Lopes Ramos. Numa aproximação à perspetiva museológica no Museu Histórico Nacional, no Rio de Janeiro, entre 1922 e 1959, que traduz a intervenção de Gustavo Barroso, o seu diretor, o autor elabora um ensaio sobre a linguagem e a prática museológica, com uma forte inspiração de Roland Barthes. Fascismo não é impedir de dizer, é obrigar a dizer, segundo o autor francês - afirmação potente para analisar objetos que são dados a ver, conquanto não sejam vistos. A partir de fotos de vitrinas do Museu, percebemos que os objetos desaparecem e ressurgem como fantasmas, através das suas legendas. É a legenda - e o grafitado sobre uma delas que serve de ilustração à tese do autor. O "censor improvisado" de uma legenda é refutado pela autoritasdo diretor, usando o seu saber técnico, a sua erudição, o seu conhecimento de geologia e da arte em cidades de Portugal e em todo o Brasil. Esses conhecimentos são chamados a desautorizar quem tentara emendar uma etiqueta de um objeto. Em carta oficial, com o brasão da República, Gustavo Barroso depõe o saber de quem inconvenientemente riscara uma legenda e a pusera em causa - e demonstra quem manda. Entre o diretor do Museu Nacional e quem grafitara a etiqueta de um relicário ali existente - Vicente Racioppi, advogado e diretor do Instituto Histórico de Ouro Preto -, havia uma rivalidade pessoal mais antiga. A partir deste episódio, Francisco Régis Lopes Ramos desafia-nos a pensar o museu como lugar de domesticação das palavras face ao mutismo dos objetos - e como exercício de endoxa. As legendas dos objetos não servem apenas para identificar, mas disciplinam o olhar. Convém recordá-lo, como faz o autor, em tempos de consumo do passado, em que este é despolitizado, desarticulado e saboreado. Num tempo de estátuas postas em causa, Francisco Régis Ramos interroga-nos sobre se as sociedades democráticas precisam de monumentos - ou seja, dos consensos hegemónicos que os sustentem, superando a pretensão antiquária de tornar o passado num fragmento do presente. Fazendo saltar Nestor GarcíaCanclíni para o terreiro da relação entre os museus e a sociedade de consumo - quando a ideia de nação se tornou desnecessária, neste tardo-capitalismo que se mostra pelas marcas -, o autor também nos desafia à nova leitura do logos. As marcas da roupa já não remetem para o made in que identifica um orgulhoso país, mas para cenários de trabalho e sobre-exploração, 
em países asiáticos ou sul-americanos, onde são produzidos por gente com poucos direitos. Tudo se torna mercadoria, mesmo o que ficou mais tempo arredado da esfera do mercado. Com Achille Mbembe, resgata-se a ideia de um anti-museu, que supere o espaço de neutralização e domesticação da primeira vida dos objetos, que já tiveram pujança e outras articulações. Nos museus, ficamos a saber com Mbembe, dá-se uma mutação no valor do objecto; assim, é preciso um anti-museu, um lugar-outro «da hospitalidade radical», que pressupõe uma anti-história - ou, de novo, uma história a contrapelo, no sentido de Walter Benjamim, aqui evocado. Só assim, a partir desse lugar-outro, poderá evocar um lugar com outras respirações.

Num tempo que, como assinala Enzo Traverso em algumas obras, tem uma predileção pelas vítimas, mas não pelos lutadores e insubmissos, a aproximação feita por Suene Honorato traz-nos várias surpresas. No seu texto, a abordagem do indígena brasileiro como vítima do passado esbateu uma outra, que o encara como agente histórico. Gonçalves Dias e José de Alencar, que foram os dois autores mais conhecidos do romantismo brasileiro, construíram obras literárias em que o indígena figura como vítima de um passado histórico. Já nas obras de autores como Lourenço Amazonas, Couto de Magalhães e Gonçalves de Magalhães, hoje pouco lembradas, pode-se encontrar um indígena que atua como agente histórico, em disputa com o colonizador. A análise da representação indígena nas obras desse conjunto de autores, tendo em vista a distinção entre política indigenista e política indígena permitem-Ihe discutir em que medida a produção do reconhecimento (a política literária) tem implicações nos modos de se pensar a questão indígena no presente. A política indigenista, conquanto denunciasse a violência do contacto colonial, decorria de cima para baixo, convertendo os indígenas em responsáveis pela própria extinção, tratando-se de seres passivos no que concerne às atrocidades que sofreram. Para o romantismo brasileiro, o fulcro está na edificação da nação, e o genocídio indígena é subtilmente encarado como necessário para construir a pátria. Essa pátria resulta da miscigenação dos brancos com os índios, que serão os pilares da identidade brasileira, de que os negros são excluídos. O indígena, demonstra Suene Honorato, tem de ser "morto" para a construção nacional após a independência, para não ser identificado com as revoltas que então eclodiam. É assim, por exemplo, com duas das obras de José de Alencar. Em O Guarani, surge um casal formado por uma branca e um índio, caracterizado como "um cavalheiro português no corpo de um selvagem». Em Iracema, a civilização triunfa com a aniquilação do índio. A religião é encarada como civilizadora, em linha direta com a Carta de Pero Vaz de Caminha. A beleza do 
morto, como the chamam Revel e de Certeau, emerge dessa raça extinta, com os povos indígenas fixados num passado que havia que superar. A autora defende que foram esquecidos os autores que, no romantismo descreveram indígenas insurretos, e narraram episódios de revolta, ou discursos contundentes contra a dominação colonial portuguesa. A projeção no imaginário atual, conquanto tenha sido promovida legislação em 2008 que encaminharia para uma visão distinta do passado brasileiro, continua herdeira desse cânone romântico, que emerge nos discursos científicos, mediáticos, cinematográficos, jornalísticos, publicitários, com os povos indígenas a continuarem excluídos e fixados no passado.

Da fixação na literatura, transita-se para a música e para a cultura expressiva do sul de Portugal. Entre resistência e modos de expectativa, a antropóloga Dulce Simões remete-nos para uma modalidade dessa mesma cultura expressiva. O Cante Alentejano está inscrito na Lista Representativa do Património Cultural e Imaterial da Humanidade da UNESCO desde novembro de 2014, o que criou expetativas nos detentores da herança cultural. Essa esperança emana da vontade coletiva pela dignificação de uma expressão cultural de homens e mulheres com formas próprias de ação, e com conquistas que lhes são inerentes. Neste artigo, o passado impõe-se como elemento unificador de uma "comunidade de partilha", definida pela distribuição de espaços, tempos e tipos de atividade que determinaram a maneira de uma classe subalternizada comunicar e fazer política. A autora analisa a tensão progressiva entre experiência e expetativa, a partir da multiplicidade de relações sociais e políticas inerentes à hierarquização, ao domínio dos saberes musicais e às características da sua organização no tempo e no espaço. Os tipos de mudanças que advieram da classificação pela UNESCO, e a apreensão de dados a respeito do canto alentejano, como forma de resistência, convidam a pensar quem define e manipula na contingência, e com que finalidade, os sistemas simbólicos em determinados tempos históricos.

Com o texto de Cristina Nogueira, o papel e os agentes da recordação são remetidos para um momento público comemorativo de enorme importância, numa povoação de matriz operária do centro de Portugal, com uma reputação firmada na história da resistência: a Marinha Grande. Decorridos 85 anos sobre uma greve operária, que teve lugar no dia 18 de Janeiro de 1934, a historiadora assistiu em 2019 à cerimónia que localmente evocou essa data, com dezenas de pessoas junto ao cemitério local. Numa encenação que relembra o papel dos trabalhadores da indústria vidreira local nessa luta, um homem usava a indumentária desse tempo e havia uma 
bicicleta com uma cesta de comida, como era habitual há 85 anos. A lista com todos os nomes dos envolvidos na luta que se encontram enterrados no cemitério foi então lida por dirigentes do sindicato, e foram deixadas flores - cravos vermelhos, muito associados à data fundadora da transição portuguesa para a democracia, o 25 de Abril de 1974. Entre a memória localizada e coletiva, e a memória social, que implica o envolvimento de políticas públicas e a inscrição feita por elas, a autora interroga o papel da cerimónia, bem como do grupo que recorda, e o impacte da luta num tempo longo. Em obra recente, Enzo Traverso aponta a melancolia como característica da esquerda do século XXI, por não ter novas esperanças coletivas no horizonte. Neste caso, a melancolia poderá estar a ser contrariada nos exemplos de lutas que se inscrevem na história dos territórios. O tempo histórico surge aqui pensado no plural através da multiplicidade de tempos que se sobrepõem em interações que constantemente remetem para as suas dimensões entre passado e futuro.

Atílio Bergamini escreve a partir da literatura, entendida como resistência ao genocídio cotidiano, num bairro periférico de Fortaleza, no Ceará, onde se realizam saraus poéticos, que acompanhou entre 2014 e 2019. A poesia, eivada da força material das ideias, referida por Karl Marx, constitui-se como um veículo de resistência. O conceito de genocídio quotidiano, a partir da sugestão de Raphael Lemkin, retrabalhada mais recentemente por Daniel Feierstein é usado para interrogar alguns traços da ideia de literatura criada por saraus e coletivos culturais que se constituíram desde pelo menos 2014 na cidade de Fortaleza, capital do Ceará, no Nordeste do Brasil. Para isso, delineia as feições do que os integrantes desses coletivos denominam genocídio cotidiano. O bairro de Jangurussu tem elevados índices de mortalidade infantil, de assassínio de jovens negros, de suicídio e de «acidentes» de trabalho. Ali, nos saraus poéticos «a literatura te tira do tiro», durante sessões de microfone aberto, em que jovens denunciam a violência nas cidades brasileiras por parte do Estado e das facções, ligadas ao tráfico de armas e de droga. Os jovens dessa periferia lidam com o pior do Estado brasileiro, com a tortura, a morte, o crime capitalista mundialmente organizado.

Enquanto, na teoria da literatura tradicional, o discurso literário seria aquele que "estranha" os discursos da vida cotidiana, na teoria literária dos coletivos culturais de Fortaleza, essa mesma literatura seria o discurso que suspende o genocídio cotidiano. Ali, é uma forma de resistência organizada por parte dos jovens, que nos seus textos releem a história brasileira e da América Latina. Trata-se de uma história a contrapelo, no sentido benjaminiano, contra a repressão seletiva que atinge povos e 
devasta a morada comum, seja com indígenas e quilombolas, seja nos bairros periféricos das cidades. O totalitarismo institucional rodeia-se e investe-se das tecnologias do poder: as polícias, as facções, o mercado mundial da droga e das armas, os meios de comunicação, os lugares oligárquicos e os novos media digitais. A cultura subalternizada é, segundo o autor, impermanente e frágil, face ao genocídio quotidiano. A literatura enquadra, na peugada de Robert Redfield, retomado por James C. Scott, uma pequena tradição, com um elenco de ações de resistência, de cura, de cuidado e de protecção mútua, que são essenciais para se sobreviver.

O espaço rural português traz outras interrogações, depois de uma plenitude demográfica atingida no início da década de 1960. O interior de Portugal, devido aos processos migratórios que se acentuaram nos anos 1960-70, conduzindo para vários países da Europa aqueles e aquelas que se cansaram da pobreza, serviu de terreno à antropóloga Ema Pires e ao sociólogo Ricardo S. de Campos. Num percurso que segue a par de um conhecido texto de Jorge Luís Borges, O Aleph, os autores deixam em elipse relações com a natureza num tempo de pandemia - em mais um momento de crise, portanto - constituindo-se a aldeia como um refúgio. De que modo se habita em Mó, uma aldeia da Beira Interior, que só tem 3 casas habitadas? Que alterações trouxeram os tempos de pandemia à vida local? Como incorpora, num tempo longo, os modos de habitar atuais? Como se inserem nessa vida as catástrofes, como os incêndios, atribuíveis a processos de florestação depredadora da floresta local, iniciada ainda durante o Estado Novo? Através de duas vinhetas etnográficas, que permitem penetrar histórias de duas famílias, a partir de Norbert Elias e do tempo como «cimento que veda», os autores reforçam o argumento de uma vivência do tempo fora do tempo no contexto local.

João Carlos Louçã traz-nos uma etnografia de retorno ao seu próprio passado de militante anti-militarista. O trabalho de terreno assenta os pés num presente etnográfico que questiona o passado e os seus usos, para entrever o futuro, e comporta com frequência momentos de espanto e reconhecimento. Como refere, a antropologia sobre o porvir é um caleidoscópio de possibilidades em aberto, que aventa conexões entre mundos que se cruzam, que se desviam e que podem reencontrar-se, em trilhos imprevisíveis para a investigação que se delineou. A surpresa haveria de o encontrar num percurso de estrada por um vale, que é agora uma albufeira de barragem, nos Pirinéus do Alto Aragão, em Espanha, onde vivem pessoas que influenciaram decisivamente o movimento antimilitarista em Portugal, no final da década de 80. Este movimento contestou o serviço militar obrigatório, a 
pertença à NATO e a lógica da guerra fria, que espalhava mísseis pela Europa num braço de ferro que ninguém podia ganhar. Envolveu uma geração urbana que, depois da revolução de 1974-75, vivia o tempo da "normalização democrática» e do discurso que repudiava os "excessos da revolução". Para os jovens em torno do Movimento Tropa Não português, o exemplo espanhol da insubmissão ao serviço militar, da objeção de consciência que fez milhares de prisões no Estado vizinho, e mobilizou amplos setores, foi fonte de inspiração e cumplicidade, autêntico motor de arranque e argumento. No Estado espanhol, esse movimento antimilitarista, numa ironia da história do processo de transição para a democracia, não foi inscrito e não mereceu trabalhos de resgate, mesmo quando foi desativada a prisão de Carabanchel, na periferia de Madrid, no final da década de 1990. Mais de trinta anos depois, o encontro do antropólogo converteu a sua própria memória em material fundamental para acompanhar o tempo longo de uma vida, com movimentos sociais que ganham outras causas. Em comunidades de montanha que procuram na complexidade do presente a simplicidade de formas de vida desejadas, que concretizam utopias nas formas de produzir, trocar, educar ou decidir entre si, que transformam precariedade em possibilidade continuada, alguns dos momentos vividos há algumas décadas emergiram com estrondo.

Com o antropólogo chileno e investigador da UNAM Raúl ContrerasRomán interpelam-se os sonhos humildes da população do ValledelMezquital, no México central, e as múltiplas maneiras de ganhar a vida, num tempo longo, com o qual lida o presente etnográfico. A mudança social é contada a partir de baixo, numa população que emigra para tornar o porvir potável, ou seja, para ter «um futuro com futuro», em que há que gerir as ausências e continuar a ter um lugar como vizinho, pertencendo desde longe. Tal é inerente a situações em que houve que evitar um presente imperfeito, cheio de dilemas e paradoxos, como nota Vanessa May, citada pelo autor. $\mathrm{Na}$ comunidade de El Boxo, em que a estatuária comporta uma cruz gigante e um monumento ao dólar, a emigração foi decisiva, e o cimento é um vestígio da experiência de ter andado longe, na espera pelos futuros que se imaginaram. Enquanto humanidade, só construímos se tivermos esperança: quando o futuro se encara como aspiração legítima de mudança para uma vida melhor, tal dá forças para o atrevimento de tentar o que não se logrou ainda. Neste ensaio, percebe-se como o futuro é um exercício de imaginação, e que a antropologia do futuro, além dos exercícios de distopia, tem um terreno fértil nos sonhos humildes dos que continuam a apostar no porvir e a construir pontes, comprometidas com enredos morais de valores 
que vão além das lógicas dominantes. A vida boa, no sentido que the deu Robert Redfield, não é um estado, mas uma aspiração contínua para ganhar a vida, que é indissociável do esforço para reproduzir a vida e fazer com que ela valha a pena. Compreendê-lo, enquanto antropólogas e antropólogos, significa superar o presente etnográfico e perceber o papel da imaginação do futuro na realidade de um dado presente. A antropologia que se centra nos sonhos humildes permite conhecer a capacidade humana de se distanciar da passividade com ações concretas e práticas possíveis, desejos de pertença e compromissos entre o presente e o futuro dos que são próximos.

Neste dossiê, a proposta foi colocada entre o passado e o futuro, pois os usos do tempo continuam um terreno não pacificado para as ciências sociais. Depois de uma quase descontinuidade da produção acerca da memória, após os textos fundacionais de Maurice Halbwachs, reaparece nos anos 1980 um interesse pelo passado, pela invenção de tradições, pelos lugares de memória, por uma semântica dos tempos históricos que sobrepõe um presente contínuo à construção do futuro. Como nota Henri Rousso, desde os anos 1980 instalou-se um passado que não passa, a que Enzo Traverso interroga o modo de usar, com memórias fracas ou fortes, por vezes com perspetivas emaranhadas e melancólicas. A partir desse estado dos saberes, o desafio deste dossiê foi percorrer os usos do tempo, a relação entre experiência e expectativa, os trabalhos da memória. Os vários autores e autoras, em escalas diversas e em contextos espácio-temporais distintos, foram desafiado/as a olhar para textos, museus, relatos de vida, pedras, quotidianos, exceções, cerimónias, modos expressivos de culturas locais, modos de inscrição, de fixação e de projeção entre o passado e o futuro, com esbatimento de fronteiras disciplinares, numa orla que torna mais ativo e complexo o conhecimento. Fizeram-no em relação a tempos e lugares em que o futuro parece ausente ou indefinido, quando há otimismo a nível coletivo, ou quando se descortinam as subjetividades que se projetam em sonhos humildes. No mais pessoano dos sentidos, os usos do tempo podem ser um terraço para outra coisa ainda, baseado num porvir delineado com esperança, com futuros presentes em vez de passados presentes. 